\title{
The Impact of Climate Change Upon Winter Rainfall
}

\author{
Numan Shehadeh and Sabah Ananbeh \\ Department of Geography, Faculty of Arts, The University of Jordan, Amman, Jordan
}

Received 2012-08-30, Revised 2013-02-21; Accepted 2013-03-29

\begin{abstract}
Climatic models that project the impact of climate change upon rainfall in the Eastern Mediterranean region predict that the negative impact will be more pronounced upon winter rainfall rather than Fall or Spring rainfall where instability conditions become more pronounced. Those models, also, predict that, due to the great geographical diversity, projected rainfall trends in the above region will show great spatial variability. Therefore, this study aims to analyze the possible impact of climate change upon winter rainfall (December, January and February) in Jordan. Data from six meteorological stations that represent well the spatial variation of rainfall in the country is used. Various statistical techniques are applied in this study including, linear regression, t- test, moving averages and CUSUM charts. Results of the analysis reveal a decreasing rainfall trend in all the sample stations. However, the decreasing trends are significant at the 0.05 level in three stations only (Salt, Amman and Irbid). The negative impact of climate change upon winter rainfall totals in the northern and central parts of Jordan, where most of winter rainfall is associated with Mediterranean depressions, is statistically significant at the 0.05 level. However, such impact is not significant in the southern and eastern parts of the country, where a greater portion of winter rainfall is associated with khamasini depressions and instability conditions. Further research analyzing the impact of climate change upon other climatic elements such as temperature, relative humidity and dust storms is needed.
\end{abstract}

Keywords: Climatic Model, Storm Vorticity, Regression Model, Moving Averages, Cusum Chart

\section{INTRODUCTION}

The Middle East, in general, is a region that experiences increasingly frequent droughts and suffers from a looming water supply shortage. Therefore, climate change is a very urgent issue in the region. What makes the situation worse is that most of the region is expected to become hotter, drier and experiencing more droughts Rashid et al. (2011). According to IPCC computer modeling, an estimated additional 80 million to 100 million people will be exposed to water stress by 2025 , putting more pressure on already depleted groundwater resources. The magnitude of future impacts of climate change is likely to be beyond the coping range of many communities and countries in the region like Jordan, where the negative impact of rainfall decrease could threaten the stability and national security of the country (Rashid et al., 2011).

\subsection{Study Area}

Jordan is a relatively small country with an area of $96000 \mathrm{~km}^{2}$. The geographical location of the country in the southeastern corner of the Mediterranean region makes it a transitional zone between the Mediterranean climate to the north and west and the arid climate to the south and east (Fig. 1). Jordan is considered to be one of the four poorest countries of the world in water resources. Average annual precipitation ranges from less than $50 \mathrm{~mm}$ in the southeast to more than $600 \mathrm{~mm}$ in the north (Fig. 2).

About $70 \%$ of the annual rainfall in the country falls between November and March; June through August are often rainless (Fig. 3). Rainfall varies considerably from season to season and from year to year. Precipitation is often concentrated in violent storms, causing erosion and local flooding, especially in the winter months.

Corresponding Author: Numan Shehadeh, Department of Geography, Faculty of Arts, The University of Jordan, Amman, Jordan 


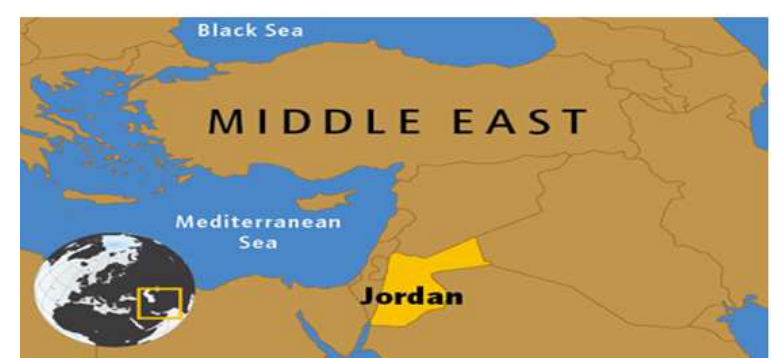

Fig. 1. The geographic location of Jordan

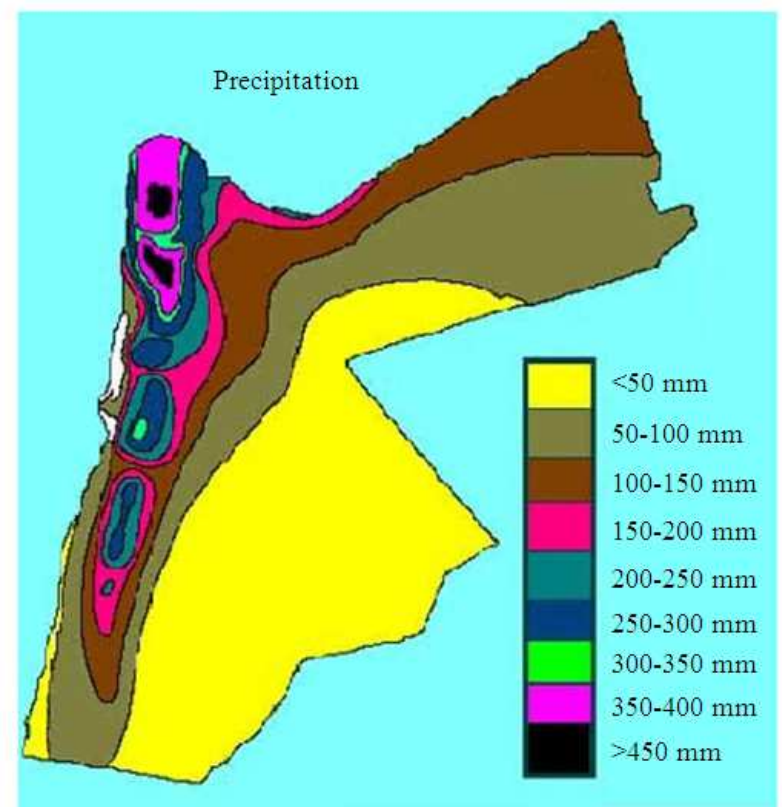

Fig. 2. Annual rainfall in Jordan

The geographical location of Jordan makes it one of the countries where climate change has strong negative impact upon rainfall which is the only renewable resource of water in the country.

\subsection{Research Problem}

To investigate spatial as well as temporal variability in rainfall trends, this study employs statistical analysis of rainfall change in all of the geographic regions of Jordan.

The main questions this study attempts to answer are:

- Is winter rainfall decreasing in Jordan?

- Is the decreasing trend predominant in all the geographic regions of Jordan?

- Is the difference between the two averages of winter rainfall for the two periods (1990-2000) and (20002010) statistically significant at the 0.05 level?

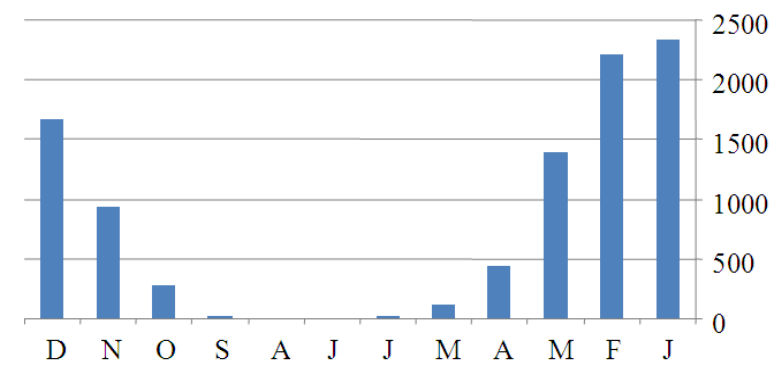

Fig. 3. Monthly distribution of rainfall in Jordan

\subsection{Study Importance}

The 2006 UNDP Human Development Report classified Jordan as one of the four most water scarce countries in the world. Jordan's Water Strategy for the period of 2008-2022 also states that Jordan is one of the four driest countries in the world (UNDP, 2006) Jordan Second Report 2009.

Rainfall is the only renewable water resource and due to demographic increase and agriculture expansion the country is expected to face by 2025 an absolute water deficit which will add to existing problems of desertification and food production. Rainfall decrease will also introduce new threats to human health, ecosystems and national economies and seriously threatens sustainable development.

Despite that a number of previous papers studied the expected impact of climate change upon rainfall in certain East Mediterranean countries (Israel, Lebanon, Syria and Jordan), the whole picture of the impact is not clear and the results are indecisive in many cases. The main reason for this confusion is attributed to the great spatial diversity in climatic characteristics in the Eastern Mediterranean region (Evans et al., 2004).

\subsection{Previous Studies}

Rainfall decrease in the Middle East is expected to have profound negative impact upon economy and political tension and could lead to war. There have been several studies of the impact of climate change upon the Eastern Mediterranean. Most of the previous studies employed climatic models to project future changes in rainfall and temperature (Evans, 2008; 2010; Evans et al., 2004; Krichak et al., 2007; Shehadeh, 1976; Anagnostopoulou et al., 2006; Lionello and Giorgi, 2007; Kafle and Bruins, 2009; Pederson, 2008; Krichak et al., 2007). Other studies used statistical techniques such as CUSUM charts, moving averages and regression models (Smadi and Zghoul, 2006; Pederson, 2008; Alpert et al., 2008; Dahamsheh and Aksoy, 2007; Al-Rimmawi et al., 2010). 
Findings of previous studies of the impact of climate change upon trends of rainfall totals in the Eastern Mediterranean, revealed that the nature of such trends and their significance are localized and vary from one place to another (Black, 2009; Kafle and Bruins, 2009; Ben-Gai et al., 1998). The study of Smadi and Zghoul (2006) of the trends at Amman and two other meteorological stations (Madaba and Mafraq) for the period 1922-2003 revealed a significant decrease in total rainfall starting in 1957. Al-Ansari et al. (1999) found a general decrease of rainfall intensity over Jordan. Black (2009) predicted that Jordan and Israel will be drier by the end of the twenty first century. They, also, found-using several regional climatic models- that the decrease in rainfall will be more pronounced in winter rainfall. The decrease of winter rainfall as projected by Black is related to the pole-ward shift of storm tracks in the eastern Mediterranean and the decrease in cyclonic vorticity in the region.

\section{MATERIALS AND METHODS}

\subsection{Data Collection}

Previous research reports that the decrease in October and November rainfall in the Eastern Mediterranean is usually small and insignificant. They, also, predict that these two months will become wetter in the future. The decrease of rainfall becomes more significant at the peak of the rainy season (December, January and February) where an approximately $40 \%$ decrease is predicted by the end of the 21st century (Black, 2009; Alpert et al., 2008) Therefore, winter rainfall, as well as, monthly totals for the months of December, January and February for the period 1990-2010 for six meteorological stations representing all of the climatic regions in Jordan is used in this study (Fig. 4). This period 1990-2010 is especially selected to avoid rainfall changes related to local factors other than those caused by climate change. The geographical coordinates as well as elevations and rainfall averages for the six stations are shown in Table 1.

Winter rainfall data is tested for randomness by computing serial correlation coefficients at lag1, but no significant coefficients are found at any of the stations used in this study which supports the hypothesis of randomness (Table 2).

\subsection{Research Hypothesis}

The research hypotheses of this study that correspond to the previous questions are:
- Winter rainfall totals are decreasing

- Decreasing trends are predominant in the northern and central regions of Jordan

- A significant difference exits between averages of rainfall for the two periods (1980-1994) and (1995-2010)

\subsection{Methods of Analysis}

Trend lines of rainfall are estimated using three statistical techniques; Linear regression, CUSUM charts and moving averages.

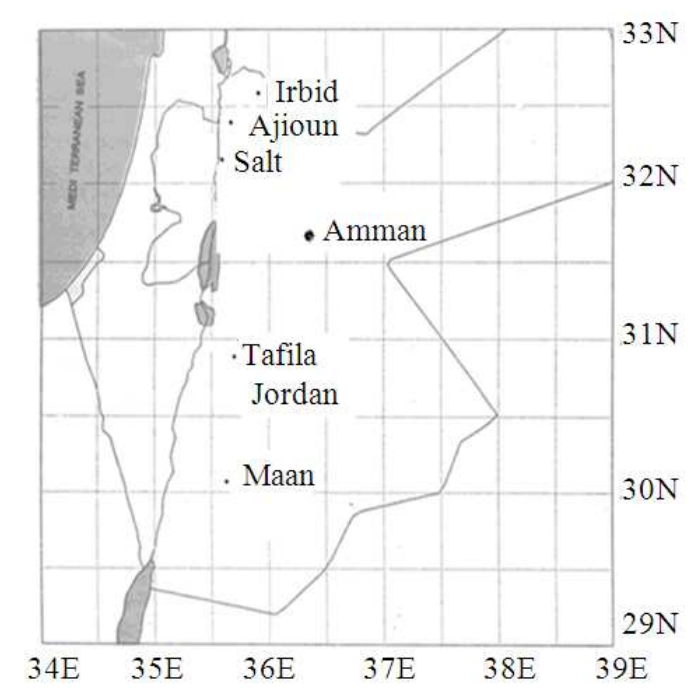

Fig. 4. Climatological stations

$\underline{\text { Table 1. Climatological stations }}$

\begin{tabular}{|c|c|c|c|c|}
\hline Station & Lat. & Long. & $\begin{array}{l}\text { Elevation } \\
\text { (m) }\end{array}$ & $\begin{array}{l}\text { Average annual } \\
\text { rainfall }(\mathrm{mm})\end{array}$ \\
\hline$\overline{\text { Irbid }}$ & $35^{\circ} 85$ & $32^{\circ} 55^{\prime}$ & 616 & 469 \\
\hline Salt & $32^{\circ} 20$ & $35^{\circ} 44^{\prime}$ & 796 & 543 \\
\hline Amman & $31^{\circ} 59$ & $35^{\circ} 59^{`}$ & 780 & 268 \\
\hline Ajlun & $32^{\circ} 22$ & $35^{\circ} 45$ & 1150 & 586 \\
\hline Maan & $35^{\circ} 75$ & $30^{\circ} 12^{\prime}$ & 1069 & 41 \\
\hline Tafileh & $30^{\circ} 50$ & $35^{\circ} 38$ & 1260 & 208 \\
\hline
\end{tabular}

Table 2. Serial correlation coefficients

\begin{tabular}{|c|c|c|c|c|c|}
\hline \multicolumn{3}{|c|}{ 1st Group of stations } & \multicolumn{3}{|c|}{ 2nd Group of stations } \\
\hline Station & $\mathrm{r}_{\mathrm{s}}$ & sig & Station & $\mathrm{r}_{\mathrm{s}}$ & sig \\
\hline Irbid & 0.048 & 0.76 & Ajlun & 0.029 & 0.85 \\
\hline Salt & 0.029 & 0.85 & Maan & -0.180 & 0.85 \\
\hline Amman & 0.029 & 0.85 & Tafila & -0.160 & 0.30 \\
\hline
\end{tabular}

rs = Serial Correlation Coefficient; sig $=0.05$ 


\subsection{Linear Regression}

Linear regression is usually used to model the relationship between two variables by fitting a least square linear equation to observed data (Equation 1). One variable is considered to be an explanatory or independent variable $(\mathrm{X})$ and the other is considered to be a dependent variable (Y). In this research, the explanatory variable is time (winter/month) and the dependent variable is total winter or monthly rainfall. Significance of the trend line is tested at 0.05 level:

$$
\begin{aligned}
& \mathrm{Y}=\mathrm{a}+\mathrm{bx}+\mathrm{e} \\
& \mathrm{a}=(\Sigma \mathrm{Y}-\mathrm{b}(\Sigma \mathrm{X})) / \mathrm{N} \\
& \mathrm{b}=(\mathrm{N} \Sigma \mathrm{XY}-(\Sigma \mathrm{X})(\Sigma \mathrm{Y})) /(\mathrm{N} \Sigma \mathrm{X} 2-(\Sigma \mathrm{X}))
\end{aligned}
$$

\subsection{Cusum}

Cusum charts, introduced by Page (1954), are widely used in statistical studies to detect small changes in the main trend of any time series. The CUSUM technique is used in this study to perform a change point analysis by computing cumulative sum charts for seasonal rainfall deviations from the mean (Table 3). A CUSUM chart is drawn for each station to detect process shifts; If a trend develops in the chart, it shows that the process has shifted. As used in this study, the CUSUM function is used to compute cumulative deviations $(\mathrm{d})$ of seasonal rainfall totals $\left(\mathrm{X}_{\mathrm{i}}\right)$ from the seasonal mean (Equation 2). Mean seasonal rainfall for each station was used in computing the CUSUM chart as the target value.

A segment of the CUSUM chart with an upward slope indicates that rainfall values are increasing. Likewise, a segment with a downward slope indicates that the rainfall totals are decreasing. A sudden change in the direction of the CUSUM indicates a sudden shift in average rainfall. A period where the CUSUM chart follows a relatively horizontal path indicates a period where there is no change in the average. One standard and two standard deviations are used to judge the significance of the shifts.

\subsection{Moving Averages}

The moving averages technique is one of the main methods used in time series analysis to smooth out noise (short-term fluctuations) and highlight the trend line and long term fluctuations. It is a type of response filter used to analyze a set of data points by creating a series of averages of different subsets of the full data set. A moving average is a set of numbers, each of which is the average of the corresponding subset of a larger set of data points.
Table 3. Computing CUSUM for rainfall totals in irbid

\begin{tabular}{lcrr}
\hline Year & Monthly(X) & d (X-X) & Cumsum (d) \\
\hline 1995 & 91.0 & -130.6 & -130.6 \\
1996 & 173.0 & -48.6 & -179.1 \\
1997 & 325.0 & 103.4 & -75.8 \\
1998 & 160.0 & -61.6 & -137.4 \\
1999 & 142.0 & -79.6 & -217.0 \\
2000 & 313.0 & 91.4 & -125.6 \\
2001 & 209.0 & -12.6 & -138.2 \\
2002 & 384.0 & 162.4 & 24.3 \\
2003 & 419.0 & 197.4 & 221.7 \\
2004 & 236.0 & 14.4 & 236.1 \\
2005 & 256.0 & 34.4 & 270.5 \\
2006 & 22.0 & -199.6 & 70.9 \\
2007 & 176.0 & -45.6 & 6.3 \\
2008 & 203.0 & -18.6 & 6.7 \\
2009 & 210.0 & -11.6 & -4.9 \\
2010 & 226.5 & 4.9 & 0.0 \\
\hline
\end{tabular}

Table 4. Seven years moving average for seasonal rainfall in Amman

\begin{tabular}{lc}
\hline Data & Moving average \\
\hline 580.000 & 58 \\
181.000 & 304 \\
248.667 & 384 \\
220.250 & 135 \\
209.200 & 165 \\
180.667 & 38 \\
173.000 & 127 \\
194.286 & 207 \\
165.000 & 99 \\
123.000 & 90 \\
130.857 & 190 \\
126.571 & 135 \\
158.286 & 260 \\
178.714 & 270 \\
164.857 & 110 \\
177.714 & 189 \\
181.857 & 119 \\
173.714 & 133 \\
177.571 & 162 \\
158.143 & 124 \\
128.571 & 63 \\
\hline
\end{tabular}

The moving averages is usually computed as follows; given a series of numbers and a fixed subset size, the first element of the moving average is obtained by taking the average of the initial fixed subset of the number series. Then the subset is modified by "shifting forward", that is excluding the first number of the series and including the next number following the original subset in the series. This creates a new subset of numbers, which is averaged. This process is repeated over the entire data series. The plot line connecting all the (fixed) averages is the moving average. QI Macros SPC Software for Excel is used in this research for computing and drawing graphs for the moving averages of rainfall records used in this research (Table 4). The time period used for computing the trend lines is seven years.

\subsection{T-Test}

The time series of rainfall for each station is divided into two equal parts and the average rainfall for each part 
is computed and compared to the average of the other part. The t- test was used to test the significance of the difference between the two means at the level of 0.05 :

Where:

$$
\mathrm{t}_{(\mathrm{x} 1-\mathrm{x} 2)}=\frac{\overline{\mathrm{X}}_{1}-\overline{\mathrm{X}}_{2}}{\sqrt{\frac{\mathrm{S}_{1}^{2}}{\mathrm{~N}_{1}}}+\frac{\mathrm{S}_{2}^{2}}{\mathrm{~N}_{2}}}
$$

$\mathrm{S}=$ Standard deviation

$\mathrm{N}=$ Number of data points

$$
\bar{Y}=\text { Average rainfall }
$$

\section{RESULTS AND DISCUSSION}

\subsection{Results of Trend Analysis}

Results of the regression analysis suggest that the six rainfall stations are divided into two main groups; the first group comprising (Irbid, Amman and Salt). The second group of stations includes (Taffila, Maan and Ajlun).

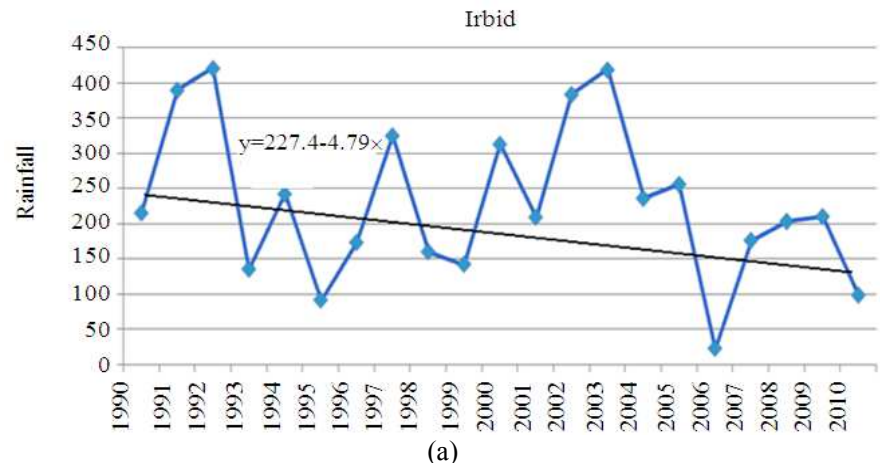

(a)

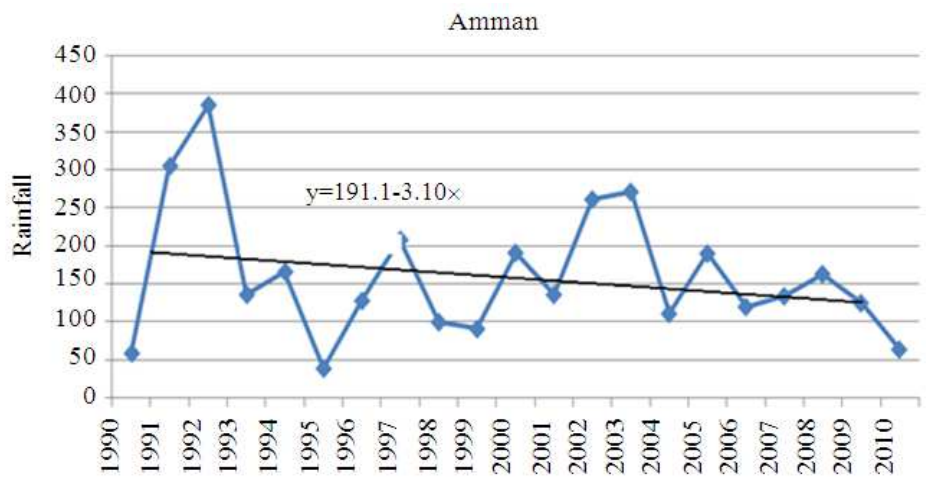

(b)

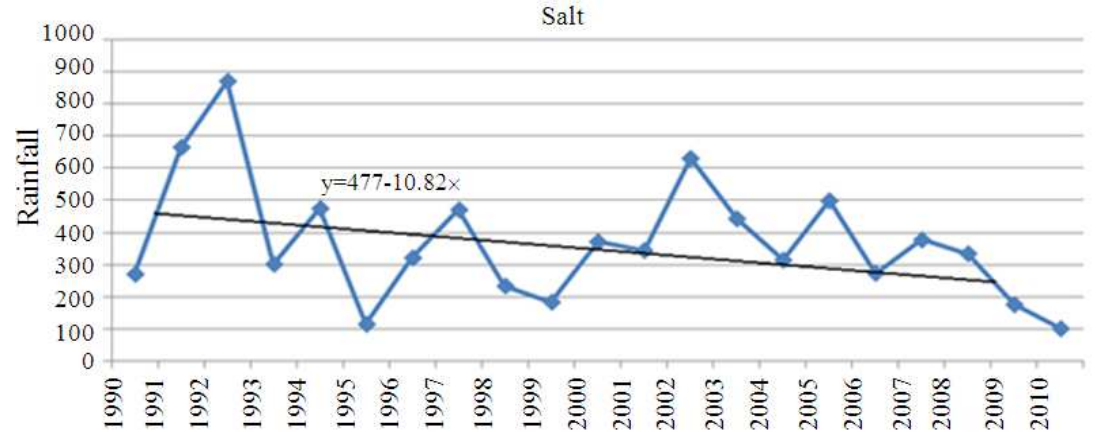

(c)

Fig. 5. Linear regression of winter rainfall in the three stations of the first group 
Numan Shehadeh and Sabah Ananbeh / American Journal of Environmental Science 9 (1): 73-81, 2013

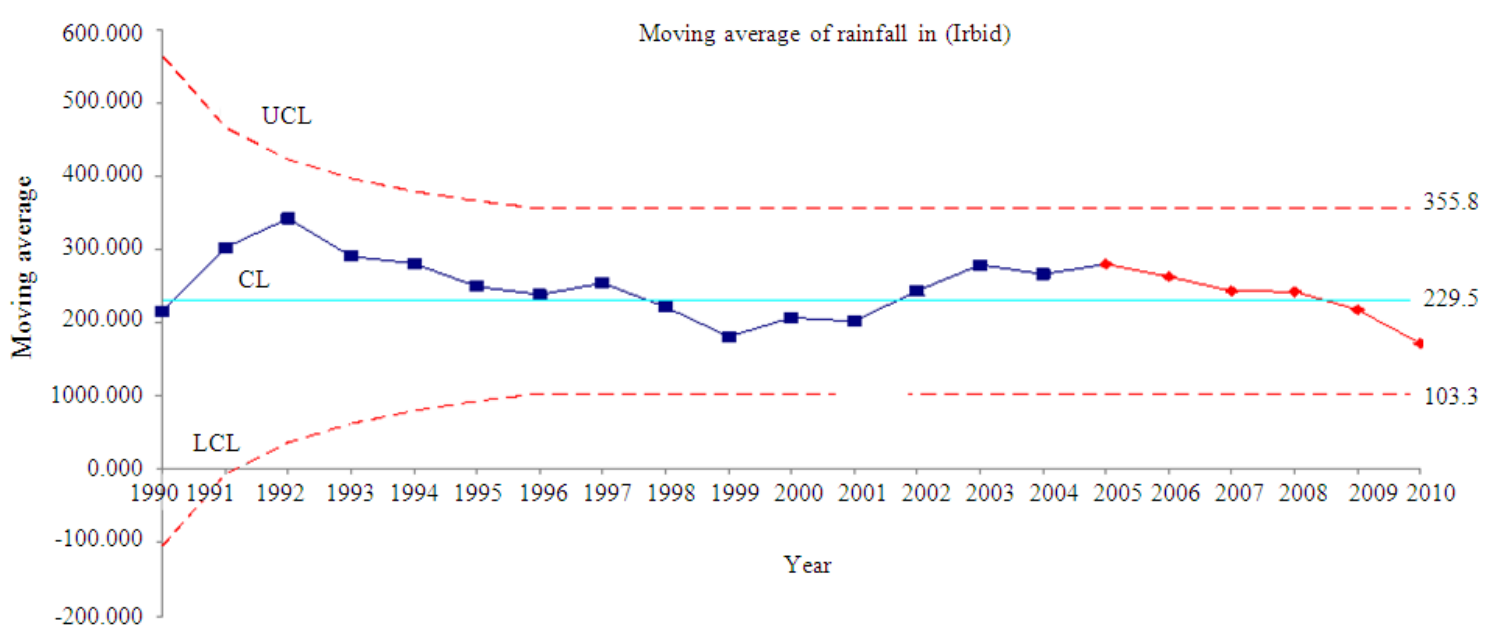

(a)

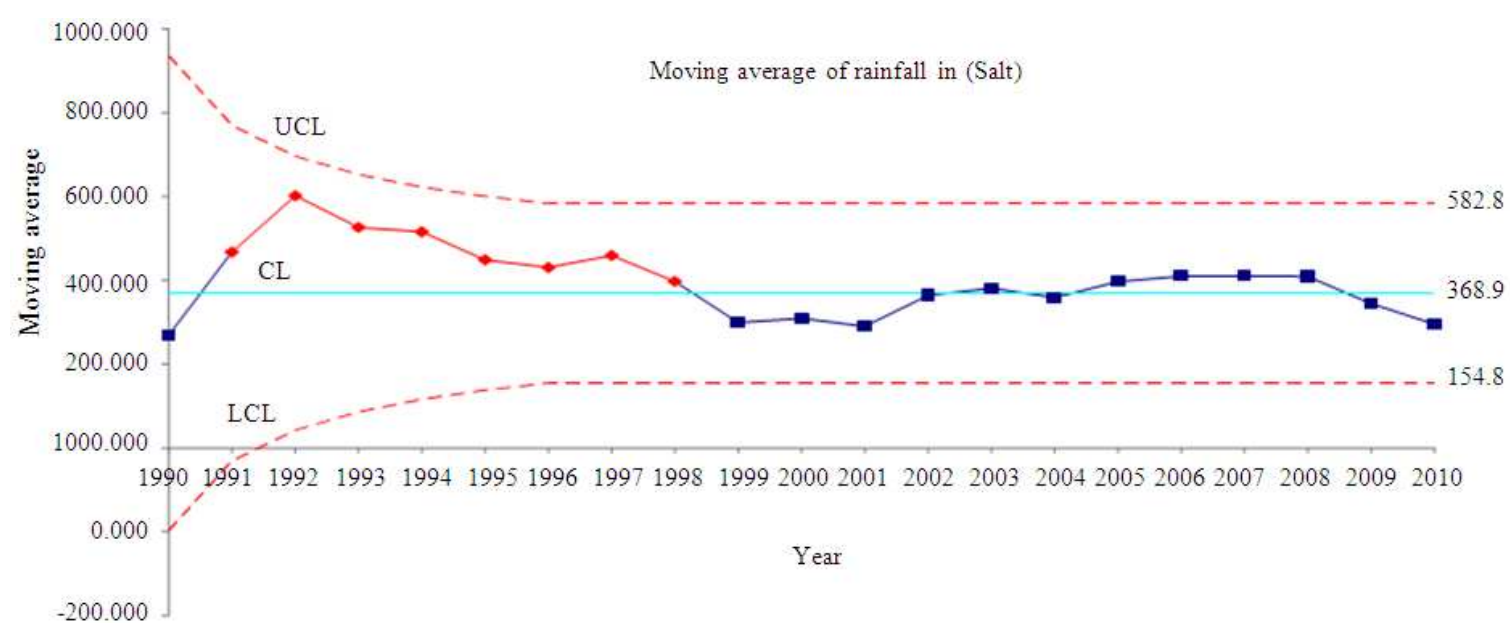

(b)

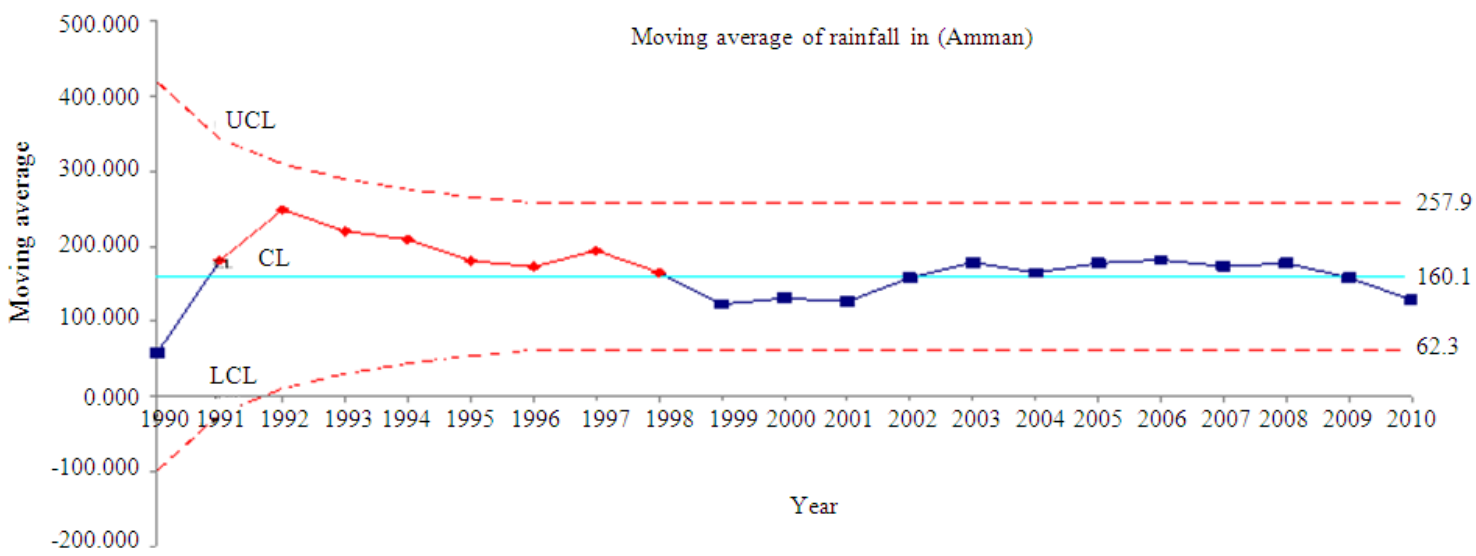

(c)

Fig. 6. Moving averages of seasonal rainfall in the stations of the first group 
Irbed
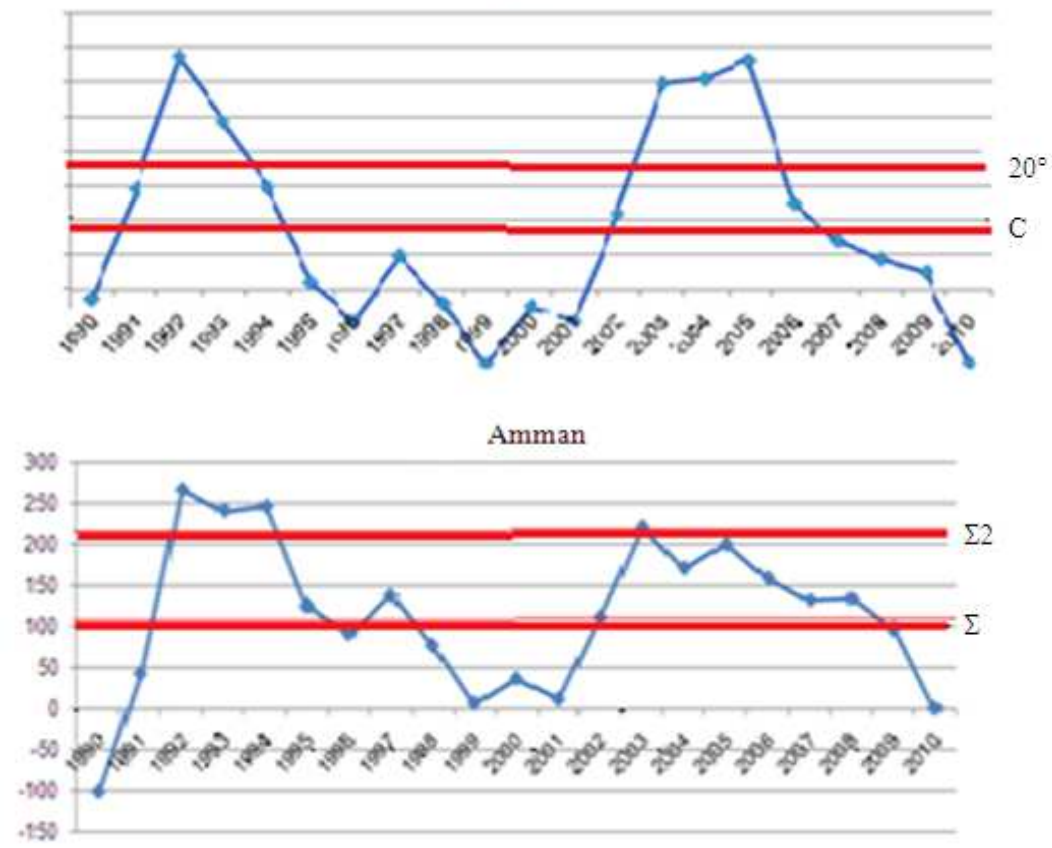

Salt

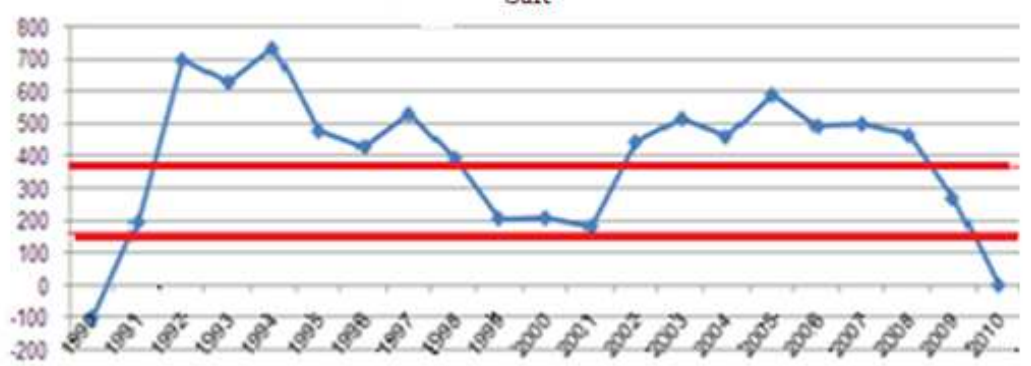

Fig. 7. Normalized CUSUM charts for seasonal rainfall at the three stations of the first group

Rainfall in the first group of stations shows significant negative trends, while the second group of stations doesn't show any significant trend.

Figure 5 illustrates decreasing winter rainfall in the three stations of the first group (Salt, Irbid and Amman). The decrease is more evident after the year 2001/2002. Linear regression Trends, illustrated as straight lines, show significant decrease at the 0.05 level of significance. The rate of decrease is stronger in Salt than in the other two cities Table 5. However, regression analysis for the last ten years of record (2000-2010) reveals significant negative trends at less than the 0.05 .
Table 6 illustrates that the decrease in January rainfall which supports the findings of previous projections of climatic models that most of the decrease of rainfall in the Eastern Mediterranean is occurring in the months of peak rainfall rather than in other months (Black, 2009).

\subsection{Results of the T-Tast}

Table 7 clearly shows the significance of the difference between seasonal rainfall means for the two periods (1990-2000) and (2000-2010). None of the tvalues is significant at 0.05 , but all of them have negative values which supports the hypothesis of decreasing rainfall trends. 
Table 5. Rainfall regression trends

\begin{tabular}{lllll}
\hline & $1990-2010$ & & $2000-2010$ & \\
Station & b & Sig. & b & Sig. \\
\hline Irbid & -4.79 & 0.24 & -21.0 & 0.04 \\
Salt & -10.80 & 0.11 & -28.1 & 0.03 \\
Amman & -3.10 & 0.33 & -11.2 & 0.05 \\
\hline
\end{tabular}

Table 6. Regression coefficient (b) for january rainfall in the first group of stations

\begin{tabular}{lrcc}
\hline Station & $\mathrm{b}$ & $\mathrm{t}$ & Sig. \\
\hline Irbid & -3.905 & 2.312 & 0.032 \\
Salt & -5.092 & 2.324 & 0.031 \\
Amman & $-0,929.000$ & 1.357 & 0.502 \\
\hline
\end{tabular}

Table 7. Differences between seasonal rainfall means for the two periods (1990-2010) and (2000-2010)

\begin{tabular}{lllrl}
\hline & $\bar{X}$ & $\bar{X}$ & & \\
Station & $1990-2000$ & $2000-2010$ & \multicolumn{1}{c}{$\mathrm{t}$} & sig. \\
\hline Irbid & 229.4 & 242.8 & -2.60 & 0.79 \\
Salt & 389.6 & 375.1 & 0.170 & 0.86 \\
Amman & 160.7 & 169.2 & -0.217 & 0.83 \\
Ajlun & 408.2 & 396.8 & 0.140 & 0.88 \\
Maan & 152.1 & 159.6 & -0.220 & 0.82 \\
Tafile & 157.3 & 159.6 & -0.070 & 0.94 \\
\hline
\end{tabular}

\subsection{Analysis of the Moving Averages}

Figure 6 illustrates the nature of seven years moving average of seasonal rainfall in the three stations of the first group. The decreasing trend of the three moving averages is very clearly shown especially in Irbid and Salt.

\subsection{Results of CUSUM Analysis}

Figure 7 shows normalized CUSUM charts for seasonal rainfall at the three stations of the first group (Irbid, Amman and Salt). As shown in the previously mentioned graph, the two turning points are statistically significant at the two levels of (o) and (2o). Normalization of the CUSUM charts was accomplished by dividing the seasonal rainfall totals for each rainfall station by their standard deviation (o). This process is justified because of the normal distribution of the seasonal rainfall.

\section{CONCLUSION}

The main conclusions of this study could be summerized as follows:

- Climate change in the Eastern Mediterranean has statistically negative impact upon winter rainfall in the northern and central parts of Jordan
- The negative impact of climate change upon winter rainfall in the arid and semi-arid areas of eastern and southern areas of Jordan has no statistical significance

- The negative impact of climate change is linked to the northern shift of the Mediterranean winter depressions, rathher than to the Spring and late Fall khamasini depressions and atmospheric instability conditions

\section{REFERENCES}

Al-Ansari, N., E. Salameh and H. Al-Omari,1999. Analysis of rainfall in the badia region. Jordan Res.

Alpert, P., S.O. Krichaka, H. Shafir, D. Haim and I. Osetinsky, 2008. Climatic trends to extremes employing regional modeling and statistical interpretation over the E. Mediterranean. Global Planetary Change, 63: 163-170. DOI: 10.1016/j.gloplacha.2008.03.003

Al-Rimmawi, H., M. Ghanem and S. Ibrahim, 2010. Rainfall trends in the district of Ramallah and AlBireh, Palestine. J. Water Res. Protect., 2: 345-352. DOI: $10.4236 /$ jwarp.2010.24040

Anagnostopoulou, C., K. Tolika, H. Flocas and P. Maheras, 2006. Cyclones in the Mediterranean region: Present and future climate scenarios derived from a general circulation model (HadAM3P). Adv. Geosci., 7: 9-14.

Ben-Gai, T., A. Bitan, A. Manes, P. Alpert and S. Rubin, 1998. Spatial and temporal changes in rainfall frequency distribution patterns in Israel. Theoretical Appl. Climatol., 61: 177-190. DOI: $10.1007 / \mathrm{s} 007040050062$

Black, E., 2009. The impact of climate change on daily precipitation statistics in Jordan and Israel. Atmospheric Sci. Lett., 10: 192-200. DOI: $10.1002 /$ asl.233

Dahamsheh, A. and A. Aksoy, 2007. Structural characteristics of annual precipitation data in Jordan. Theoretical Appli. Climatol., 88: 201-212. DOI: 10.1007/s00704-006-0247-3

Evans, J., 2008. 21st century climate change in the Middle East. Climatic Change, 92: 417-432.

Evans, J.P., 2010. Global warming impact on the dominant precipitation processes in the Middle East. Theoretical Appl. Climatol., 99: 389-402. DOI: 10.1007/s00704-009-0151-8

Evans, J.P., R.B. Smith and R.J. Oglesby, 2004. Middle east climate simulation and dominant precipitation processes. Int. J. Climatol., 24: 1671-1694. DOI: 10.1002/joc. 1084 
Kafle, H. and H.J. Bruins, 2009. Climatic trends in Israel 1970-2002: Warmer and increasing aridity inland. Climatic Change, 96: 63-77. DOI: 10.1007/s10584009-9578-2

Krichak, S.O. P. Alpert, K. Bassat and P. Kunin, 2007. The surface climatology of the eastern mediterranean region obtained in a three-member ensemble climate change simulation experiment. Adv. Geosci., 12: 67-80. DOI: 10.5194/adgeo-1267-2007

Lionello, P. and F. Giorgi, 2007. Winter precipitation and cyclones in the mediterranean region: Future climate scenarios in a regional simulation. Adv. Geosci., 12: 153-158.

Page, E.S., 1954. Continuous inspection schemes. Biometrika, 41: 100-115.
Pederson, D., 2008. Will climate change reduce or increase middle east rainfall.

Rashid, M., J.J. Pereira, R.A. Begum, S. Aziz and M.B. Mokhtar, 2011. Climate change and its implications to national security. Am. J. Environ. Sci., 7: 150160. DOI: 10.3844/ajessp.2011.150.160

Shehadeh, N., 1976. Variability of rainfall in Jordan. Dirasat Res. J., 3: 67-85.

Smadi, M.M. and A. Zghoul, 2006. A sudden change in rainfall characteristics in Amman, Jordan during the Mid 1950s. Am. J. Environ. Sci., 2: 84-91. DOI: 10.3844/ajessp.2006.84.91

UNDP, 2006. Human development report, 2006. United Nations Development Programme, New York. 